Viso - Cadernos de estética aplicada

Revista eletrônica de estética

ISSN 1981-4062

No 17, jul-dez/2015

http://www.revistaviso.com.br/
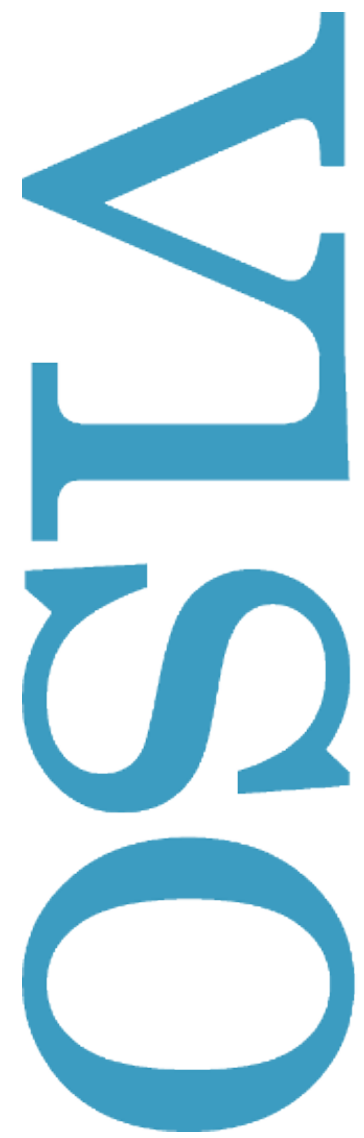

\title{
A personagem de ficção e o mundo digital Bernardo Barros Oliveira
}




\section{RESUMO}

\section{A personagem de fiç̧ão e o mundo digital}

Este artigo é o relato da pesquisa que venho desenvolvendo há um ano, a respeito da relação entre o tema da experiência e o das modificações das formas narrativas através de exemplos do mundo atual, cuja base teórica primeira são os ensaios da década de 1930 de Walter Benjamin. O foco desta foi inicialmente o modo de recepção das narrativas audiovisuais na internet, as séries, assistidas no modo stream e o aspecto compulsivo que este frequentemente apresenta. Em seguida, esta pesquisa tomou o rumo de analisar a grande preeminência da figura da personagem nas narrativas seriadas, em detrimento do arco estruturante de um enredo fortemente voltado para a inteligibilidade apoiada em um fim, mas o fenômeno analisado foi a recepção ao romance da americana Jennifer Egan, A visita cruel do tempo, de 2010, que conseguiu radicalizar o que está presente na estrutura e na recepção das séries, produzindo, no entanto, uma experiência estética do tempo, tal como é possível contemporaneamente. Por fim, o artigo tenta formular alguns elementos para analisar os motivos desta preferência contemporânea por narrativas com fraca estruturação em termos de enredo em sentido clássico, porém fortes na construção de personagens e situações. o sentido do controle e da repetição insistente, ambas necessárias ao poeta/narrador.

Palavras-chave: experiência - narrativa - personagem - contemporaneidade 


\section{ABSTRACT}

\section{The Fictional Character and the Digital World}

This article is the report of the research I have developed through the last year, regarding the relationship between the issue of the experience and the modifications of the narrative forms, through examples of current world. The theoretical first basis are the Walter Benjamin's essays of the decade of 1930. The focus of this was initially the reception modality of the audiovisual narratives in the internet, the series, watched in the stream mode and the compulsive aspect that this often presents. Then, this research took the course of analyzing the great preeminence of the figure of the character in the serial narratives, to the detriment of the structuring of a plot arc strongly focused at the intelligibility supported in an ending. The phenomenon analyzed was the reception to the novel of the American Jennifer Egan, A Visit from the Goon Squad, from 2010, who succeeded in radicalising what is contained in the structure and in the reception of the series, producing, however, an aesthetic experience of time as is possible contemporaneously. Finally, the article attempts to formulate some elements to analyze the reasons of this contemporary preference for narratives with poor structuring in terms of plot in the classic sense, however strong in construction of characters and situations.

Keywords: experience - narrative - character - contemporaneity 


\section{OLIVEIRA, B. "A personagem de ficção e o mundo digital”. In: Viso: Cadernos de estética aplicada, v. IX, n. 17 (jul-dez/2015), pp. 200-220.}

DOI: 10.22409/1981-4062/V17i/214

Aprovado: 13.02.2016. Publicado: 27.02.2016.

(C) 2016 Bernardo Barros Oliveira. Esse documento é distribuído nos termos da licença Creative Commons Atribuição-NãoComercial 4.0 Internacional (CC-BY-NC), que permite, exceto para fins comerciais, copiar e redistribuir o material em qualquer formato ou meio, bem como remixá-lo, transformá-lo ou criar a partir dele, desde que seja dado o devido crédito e indicada a licença sob a qual ele foi originalmente publicado.

Licença: http://creativecommons.org/licenses/by-nc/4.0/deed.pt_BR

Accepted: 13.02.2016. Published: 27.02.2016.

(C) 2016 Bernardo Barros Oliveira. This document is distributed under the terms of a Creative Commons Attribution-NonCommercial 4.0 International license (CC-BY-NC) which allows, except for commercial purposes, to copy and redistribute the material in any medium or format and to remix, transform, and build upon the material, provided the original work is properly cited and states its license.

License: http://creativecommons.org/licenses/by-nc/4.0/ 
Considerando que ninguém, já há muito tempo, se reúne em frente ao fogo para contar e ouvir histórias que vêm de longe, que também a fase do romance ou da narrativa escrita já deixou seu apogeu para trás, e que mesmo o cinema, a forma de contar histórias mais importante do século passado, já entra em uma fase declinante, não cabe nos perguntarmos o porquê de ainda persistir alguma forma de narrar? Estas formas existem, sem dúvida nenhuma, e a elas são dedicadas muitas horas de nossas vidas. Não se trata de atividade em desaparecimento, esta de seguir uma história. Walter Benjamin, em seu célebre ensaio sobre o contador de histórias, detecta uma atrofia na capacidade de ouvir, memorizar e recontar histórias em situações de oralidade, nas quais predomina o caráter prático de engajamento com situações de vida, onde o que conta é a resposta à pergunta "o que fazer?". ${ }^{1}$ A prática real da narrativa oral é parente do conselho e também do provérbio, duas formas discursivas ainda mais desvalorizadas e deslocadas no mundo moderno, povoado pelo sujeito monádico produzido pelas condições de vida nas sociedades industriais, que não sabe reunir suas experiências e transmiti-las, como é próprio de se fazer com experiências. Essa prática já tinha de fato desaparecido nos anos 30 do séc. $X X$, época da escrita do ensaio que mostrava o caráter problemático da experiencialidade, do recolhimento e transmissão do tempo vivido como experiência compartilhável, à luz das condições contemporâneas de vida. ${ }^{2}$ Mas o mesmo ensaio mostra que outras formas, como o romance, a short story e a reportagem informativa, encontravam, nesta mesma época, terreno propício para prosperar. Algumas formas narrativas prosperam em termos de recepção significativa, enquanto outras caem lentamente em desuso, permanecendo apenas enquanto objeto de um cultivo muito especializado. O processo destas transformações, como Benjamin diz no ensaio "A obra de arte na era de sua reprodutibilidade técnica", referindo-se às artes em geral, é bem mais lento do que as mudanças visíveis no mundo das técnicas. ${ }^{3}$ Os movimentos do que ele chama de "as massas" (evitando o termo "povo") em direção ao cinema e à sua linguagem fundada no corte e na montagem e em sua recepção coletiva, não seria fruto de simples atração por novidade ou resultado de investimento publicitário. O cinema e sua linguagem seriam homogêneos esteticamente, entre outras coisas, com o choque, que por sua vez seria o elemento predominante nos novos hábitos que modulavam a percepção sensorial, o ritmo específico que pautava o cotidiano do habitante das recém agigantadas cidades do universo europeu e norte-americano, primeiros palcos do surgimento das anônimas multidões modernas.

Pegando carona no mesmo gesto de Benjamin em seus ensaios dos anos 1930, e tentando dar a ele uma formulação minha, diria que este consiste em procurar, nas afinidades eletivas entre uma época e certas formas estéticas (quer sejam elas consideradas "arte" ou não por essa mesma época), indícios fortes do modo como são possíveis experiências naquelas condições históricas. A clareza deste gesto benjaminiano inspirou a formular uma espécie de "método" de análise de fenômenos estéticos. Não me preocupo aqui em atribuir a responsabilidade por este método a Walter Benjamin, embora considere que sua formulação deste não seja destituída de valor para compreender o conjunto dos referidos ensaios estéticos do período final do 
autor alemão. O tema da relação entre técnica e tecnologia com as formas ditas estéticas é uma constante nesses ensaios, a ponto de reduzir ou até anular a distância entre a noção de "belas artes" e a de técnica pura e simples: as obras abordadas por Benjamin se mostraram, cada vez mais, como experimentos técnicos onde se testam novas formas de habitar o espaço moderno. ${ }^{4}$ Meu interesse principal não foi usar esta formulação de um "método benjaminiano" para explicar a obra de Benjamin, mas utilizálo para observar fenômenos contemporâneos.

Esse "método" veio ao encontro de alguns acontecimentos que foram tomando corpo para mim nos últimos anos: foi o cruzamento de uma crescente obsessão com certos fatos observáveis no cotidiano coletivo com algumas antigas leituras que me levou a tentar uma espécie de "estética aplicada". Fui tomado, por volta do final da primeira década deste século, por uma estranha insistência em observar o engajamento de todos ao redor com os artefatos eletrônicos, em especial após o fenômeno do smartphone, movimento que demorou um pouco mais para me tomar e que deixou hoje muito poucos fora de sua influência. Ter demorado um pouco mais que a média para ser tragado pela tela escura das hoje onipresentes caixinhas me fez olhar como um estrangeiro, ao menos por um tempo, para os novos hábitos. Ao mesmo tempo, era recorrente o meu retorno à leitura dos ensaios tardios do pensador alemão, escritos em uma época ao mesmo tempo tão diferente da nossa e tão parecida, no entanto, em alguns de seus princípios, os anos 1930. A fermentação das duas coisas me direcionou para os engajamentos narrativos mais evidentes e cotidianos que percebia em curso ao meu redor, influenciados, talvez, pelos novos hábitos tecnológicos. Um fato veio se agregar a este cruzamento. Arraigado como fui, desde a infância, no hábito da leitura de romances, hábito esse acrescido do quase natural desdobramento por um interesse (não tão constante) pelo cinema de roteiro (essa forma híbrida ao extremo que incorpora tudo que existiu antes, em particular o romance), estranhei o entusiasmo com que alguns se referiam às séries televisivas, quase sempre americanas, a que assistiam, especialmente em canais de TV por assinatura, na mesma época. Durante alguns anos ouvi com sobranceiro desdém comentários de amigos e conhecidos a respeito de artefatos narrativos audiovisuais que eles elogiavam e com os quais estavam visivelmente engajados, e que eu classificava sob a expressão ultrapassada de "enlatados para a TV". Nisso eu já estava claramente, hoje vejo, defasado, pois aquela fase dos seriados nas TVs por assinatura representava já uma nova época desta forma narrativa. Era perceptível, por exemplo, a presença, nas locadoras de DVD, naquele tempo ainda muito importantes na vida cotidiana, de coleções inteiras dedicadas aos novos seriados, que ocupavam sessões cada vez maiores das prateleiras, visivelmente iniciando uma concorrência com os filmes feitos para o cinema. Narrativas audiovisuais seriadas era algo com que eu convivia desde a infância, e que até nossos antepassados conheceram muito bem, na modalidade áudio das rádio novelas e na versão cinematográfica dos seriados de aventura exibidos nos cinemas, e posteriormente na longa tradição brasileira das telenovelas. Podemos ir mais longe e lembrar a relação do público com os folhetins, já na Paris do séc. XIX, relação esta que se confunde em parte com a história do 
romance na segunda metade daquele século, inclusive no Brasil, pois muitas das obras mais conhecidas e cultuadas desta forma narrativa foram publicados de início como capítulos em jornais e revistas. Mas começa ali, em meados da primeira década deste nosso século, uma nova ascensão deste gênero em termos de prestígio, ao ponto em que se tornou possível, hoje, um escritor renomado como Ricardo Piglia dizer, por exemplo, que "os grandes escritores de roteiros americanos estão trabalhando em séries. Gosto muito das séries americanas. Que capacidade de fechar o capítulo, mas deixando-o aberto ao mesmo tempo!"5; ou outro escritor de prestígio como Henrique Villa Matas dizer que

decidi tomar os capitulos de Mad Men como lições para me reconciliar com o encanto de me dedicar às formas breves, de escrever contos, em suma. Reconcilie-me com a arte de contar pelo prazer de contar em si mesmo, uma atividade da qual, sem desejá-lo de todo, eu havia me afastado, talvez por me dedicar, cada dia mais, ao ensaístico. ${ }^{6}$

Com a migração de grande parte das antigas media para o mundo da rede digital, como o jornal, a música e até a leitura de livros e romances, que se acentuou na década atual, as séries passaram agora a um lugar de ainda mais destaque do que tinham antes na fase intermediária dos canais de TV por assinatura e locadoras. Os cadernos culturais da chamada "grande" imprensa davam cada vez mais destaque aos seus desdobramentos, tanto em termos de roteiro quanto em quantificações dessa modalidade de recepção. As séries começaram a migrar dos canais de TV para sites da internet, que ofereciam conteúdo no modo "stream". Trata-se de uma corrente digital de imagens onde se pode mergulhar de imediato e seguir uma história através de vários dispositivos, desde uma TV conectada à rede até o onipresente smartphone, entre outros aparelhos que nos cercam. Elas existem em profusão e em uma convivência simultânea no espaço digital, uma vez que não existe mais limitação temporal para assisti-las: elas estão "lá", disponíveis, as mais antigas e já encerradas, e as em curso ainda de produção, em blocos de temporadas inteiras. Recordo que me chamou a atenção, por exemplo, o destaque dado à exibição do último capítulo da série Breaking $\mathrm{Bad}^{\top}$ em um canal de assinatura, em setembro de 2013 , ao mesmo tempo em que eu sabia que minha filha adolescente e seu círculo de amigos assistiam à série na internet, e que o faziam, às vezes, em longas imersões no dito stream, onde era possível assistir a vários episódios encadeados. A série tinha sido iniciada em janeiro de 2008, em um canal por assinatura, e no decorrer de suas 5 temporadas teve tempo de ser tragada para o novo modo predominante de exibição, onde se tornou uma espécie de ícone do novo modo de relação com narrativas, uma aceleração compulsiva da dinâmica acima descrita por Piglia, a do prazer de pular para o próximo estágio da história. A série em questão apresentava com perfeição as duas características apontadas pelo escritor: cada capítulo é quase autônomo em si mesmo, e também abre para o seguinte como se sua razão de existir fosse apenas esta. O modo francamente preferido dos adolescentes era o de encadear o início do capítulo seguinte ao fim do anterior, sem pausa. Percebi que eles eram frequentadores assíduos de diversas séries disponíveis nesse formato online, 
no qual também assistiam a longas-metragens produzidos para o cinema, ao passo que pouco iam às salas de exibição. Mesmo no cinema, as grandes produções são hoje, quase invariavelmente, séries para exibição em salas e, posteriormente, para o stream, como é o caso de Star Wars. Decidi-me a entrar na dita corrente, a princípio como uma espécie de esteta antropólogo, logo a seguir como espectador típico, e passei a experimentar esse modo de seguir uma história, tendo assistido com dedicação à série acima referida, entre algumas outras. Percebi que nas conversas sobre séries era comum que se trocassem indicações de séries a assistir. Um dos adjetivos que acompanhavam uma série recomendada era seu caráter "viciante". Indiquei Breaking $\mathrm{Bad}$ a amigos, inclusive àqueles que, sendo professores de filosofia como eu, e cultivadores de hábitos semelhantes aos meus, terminaram por relatar os mesmos sintomas pelos quais passei: se disseram viciados nesta e em outras séries, indicavam novas produções e teciam comentários sobre "acontecimentos" ficcionais e personagens com grande interesse.

Descobri que existia, na imprensa norte-americana, um termo criado especialmente para os novos hábitos, "binge-viewing" ou "binge-watching", que remetia à ideia de embriaguez e vício, identificado especialmente com o comportamento compulsivo de assistir a diversos capítulos em sequência. ${ }^{8}$ Isso era apenas a ponta do iceberg de quase infinito material escrito disponível nas redes sobre o assunto, bastando que se soletre 0 nome "binge-watching" no teclado, atestando não só a importância atribuída a este modo de recepção de narrativas, como indicando um direcionamento de análise por parte dos articulistas, que tendem a relacionar a forma do discurso narrativo em questão (as séries), o meio onde a recepção ocorre (a internet), os hábitos moldados por ambos (o "binge") e, por fim, a influência destes novos hábitos sobre a forma de produção das novas séries. ${ }^{9}$

E assim o cruzamento de todos esses fatos acima se transformou em pesquisa acadêmica. Um pressuposto desta é que as nossas arraigadas hierarquias estéticas, que desautorizariam interesse por um fenômeno como este, não têm nada a fazer aqui. Encontrei nas reflexões de John Dewey sobre arte e experiência, escritas na mesma época que os ensaios da maturidade de Benjamin, um inesperado aliado, que cito com satisfação:

Tão vastas e sutilmente disseminadas são as ideias que situam a arte em um pedestal longínquo, que muita gente sentiria repulsa, em vez de prazer, se lhe dissessem que ela desfruta de suas recreações despreocupadas, pelo menos em parte, em função da qualidade estética destas. As artes que hoje têm mais vitalidade para a pessoa média são coisas que ela não considera artes: por exemplo, os filmes, o jazz, os quadrinhos [...]. É que a noção popular provém de uma separação entre a arte e os objetos e cenas da experiência corriqueira que muitos teóricos e críticos se orgulham em sustentar e até desenvolver. ${ }^{10}$

O foco da questão, para mim, estava no modo de recepção deste tipo de narrativa. Não 
pretendia analisar alguma série em especial, mas sim o modo como estas são vistas no novo meio tecnológico. Mas percebi que a partir do momento em que passei a me interessar pelo fenômeno da recepção às séries, alguns colegas e amigos passaram a me identificar, não sem alguma desconfiança, como uma espécie de admirador incondicional e apologeta do objeto séries-na-internet, o que eu considerava um equívoco e fruto da mesma tendência a hierarquizar e separar os objetos que atraem a nossa atenção como de arte ou de distração e entretenimento vulgar. A distinção é antiga, e Benjamin fala dela quando se ocupa da recepção ao filme nos anos 1930, quando o cinema ainda não tinha sido decididamente incluído no panteão das artes sérias. ${ }^{11} \mathrm{O}$ hábito arraigado diz: se você fala sobre um objeto estético, está fazendo o seu elogio e colocando-o no nível da "grande arte". Não se tratava bem disso, nem tampouco do seu contrário, mas sim de ver na intensidade e amplidão do fenômeno da recepção aquele tipo de jogo narrativo, de encontrar ali um indício da forma narrativa particular que a experiência tende a assumir hoje em dia. Acompanhar séries de modo compulsivo pode ser uma tentativa de experiência estética? E ela tem relação com o que Dewey chama de "objetos e cenas da experiência corriqueira"? Qual a forma desta experiência corriqueira, e o que se torna "objeto" para ela? E o que pode ter o binge-watching a ver com a forma desta experiência?

Alguns artigos na imprensa, como o acima aludido de John Jungersen, apontam para o fato de que seguir uma série, encadeando vários capítulos, o que é às vezes caracterizado como um "transe", faz esquecer de tudo o mais, até mesmo de postar e curtir as postagens dos amigos em redes sociais. $\mathrm{O}$ artigo aponta também para o fato de que o hábito dificulta a veiculação de publicidade, por causa da inexistência de brechas para a inserção destas dentro dessa nova modalidade. O que, a princípio, atraiu minha atenção nesse novo hábito de seguir narrativas foi, em primeiro lugar, o fato de ele ser fruto direto de modificações técnicas, da presença constante e a cada dia maior do mundo digital; em segundo lugar, porque representa uma espécie de disputa pela atenção no interior deste mesmo meio digital. Trata-se então de uma prova da resistência da forma narrativa, em particular da romanesca, que sobrevive e até se fortalece em um meio tão contrário à característica tendência à imersão e intensificação da arte de narrar? Será que a perspectiva da continuidade com relação a formas mais antigas de narrar e de seguir histórias é a perspectiva mais apropriada para entender o vício em séries?

É notória a distinção, presente em autores como E. M. Forster, lan Watt e Monika Fludernik ${ }^{12}$, entre narrativas que propõem mais ênfase em que sigamos a linha do enredo e as que pedem que olhemos com todo o cuidado para o desenvolvimento da personagem. Ou, melhor dizendo, para narrativas onde a linha do enredo por assim dizer brota da personagem. O paradigma dessa oposição ganha certa concretude didática na oposição drama versus romance, mas não fica só aí. O drama clássico foi o modelo para uma definição do narrativo em termos de fechamento, de forte ligação causal entre os episódios ou cenas, e de fim como o limite que confere visibilidade intelectiva para o todo 
da trama. O romance dos sécs. XVII a XIX tenderia, por sua vez, a enfatizar menos o fechamento e a ligação causal forte, procurando privilegiar o olhar que acompanha o desenvolvimento da personagem como individualidade em formação. Forster chega a minimizar o papel do fim nos romances típicos, e considera que romancistas que têm os olhos demasiadamente voltados para o desenho do enredo transformam as personagens em meros instrumentos. ${ }^{13}$

Já foi notado que seguir uma narrativa é experimentar dois tipos de temporalidade, simultaneamente. Por um lado seguir uma história é se colocar no lugar de alguém que experimenta no presente os acontecimentos e é levado a tomar decisões, sem saber onde aquilo irá terminar. Por outro lado é, também, confiar que a voz narrativa, aquela que se responsabiliza pela condução da nossa atenção para os fatos que ela escolhe, é feita por uma entidade que já sabe tudo o que aconteceu. A palavra latina narrator tem ligação com a noção de saber: narrador é um profeta às avessas, é aquele que sabe o que foi. Entre o tempo da personagem, muito mais semelhante ao nosso próprio, que nos encontramos sempre in media res, e o do narrador, que simula algo como uma compreensão de certo modo espacializada dos acontecimentos, existe uma divisão de saberes. Seguir a personagem, se colocar no presente dela, é experimentar o sabor, seja qual for, de ser ela. Mas, ao mesmo tempo, queremos fazer isso confiando que também estamos convidados a partilhar do saber panorâmico que o narrador possui, seja ele um saber grande, desmesurado até, como o dos narradores oniscientes de certos romances do séc. XIX, ou até mesmo o quase nada saber de certas narrativas contemporâneas. Mas é sempre um saber, e este nos exime de nos identificarmos em demasia com as personagens e seus destinos. Diversas narrativas, entre elas o Dom Quixote, já abordaram os perigos de um excesso de identificação. Estes dois saberes estão concentrados em dois elementos das narrativas: a concatenação dos episódios em um enredo, e a fragmentação das sensações e pontos de vista nas personagens. Eles podem ser tematizados em separado, mas na prática andam sempre juntos. Mas o fazem em proporções diferentes, variáveis segundo as necessidades de cada época.

A tradição mais arraigadamente filosófica a respeito do ato de narrar e de seguir uma história, exemplificado na antiguidade por Aristóteles em sua Poética, e contemporaneamente por Paul Ricoeur em seu monumental Tempo e narrativa, privilegia o caráter intelectual deste saber eidético concentrado no enredo. O mythos aristotélico sobrepõe-se ao carácter (não há, na Poética, nome para personagem, mas no máximo a construção verbal pratontas, "agente"), podendo, segundo o autor grego, haver tragédia sem caracteres, mas não sem enredo ${ }^{14}$, e isso é bem vindo para um olhar que busca ordem, serenidade e organização. ${ }^{15}$ Ricoeur, em uma detalhada leitura da Poética, enfatiza o par mimesis-mythos como central para construir uma definição mínima do espaço narrativo. ${ }^{16} \mathrm{~A}$ mimesis é representação de ação, e ação, tornada um todo coeso, com princípio, meio e fim, é mythos, enredo, trama dos fatos. As "metamorfoses do enredo"17, através das diversas épocas da história das narrativas, são a condição necessária, segundo Ricoeur, para que textos tão díspares quanto uma tragédia de 
Sófocles, um romance de Balzac e um "anti-romance" contemporâneo sejam membros da mesma família. Ricoeur, portanto, seguindo a pista aristotélica, coloca suas fichas na elasticidade desta noção de cunho filosófico e teorético, que avizinha o ato de seguir narrativas do de compreender um todo em suas relações internas e externas. A mesma exigência coloca lado a lado, para Ricoeur, a historiografia e a ficção: ambas são atos que articulam a diversidade dos fatos em um sistema. Claro que o termo compreensão é polissêmico e não posso aqui tentar explorar esse filão. Não pretendo reduzir a este aspecto a riqueza da obra mais seminal a respeito do ato de narrar, que é a Poética, e tampouco o da obra contemporânea mais vasta a respeito do assunto, que é Tempo e narrativa! ${ }^{18}$ Digamos apenas que essa tradição tem boas razões para privilegiar esse olhar focado na forma do enredo e em sua capacidade de esclarecimento e ensinamento no fim das contas ético, no caráter de fomentador de um conhecimento "fronético" desses cumes onde, nas palavras de Foster, reinam "a interpretação e a paz." E têm razões para olhar com desconfiança a excessiva identificação e atenção às personagens e suas idiossincrasias (neste quesito, podemos até incluir Platão e suas reflexões sobre Aquiles chorando por Pátroclo). ${ }^{19}$

Quero apenas relatar uma mudança de rumo no meu percurso: a partir de certa altura, o modelo centrado no enredo, que regeu minhas primeiras tentativas de escrever sobre o assunto, se tornou inadequado para revelar o que exatamente faz com que o interesse geral migre de formas mais fechadas e centradas em enredos, como o cinema de longametragem e mesmo o romance em sua faceta mais tradicional, para artefatos narrativos mais abertos em termos de fim, como as séries e outros. O público contemporâneo é reativo a certas experiências da literatura contemporânea, que contrariam certas expectativas, mas abraça com entusiasmo a prática de seguir histórias que podem não ter fim, como as séries.

Em meus primeiros três trabalhos, acima aludidos, insisti na pergunta sobre se as séries eram ou não uma continuação da estética do romance e do folhetim, que thes é intimamente aparentado. Seria o vício em séries, como alguns sustentam na imprensa, uma mera reedição do mergulho no ficcional que experimentamos ao não conseguirmos "largar" um romance? Minha resposta era negativa: o "vício" em séries teria sido, segundo eu mesmo, precedido pelo vício na própria internet, fruto do hábito que moldou nossa atenção e percepção, durante anos, na prática do "navegar" ou "surfar" de um site para outro, a introjeção da dispersão como princípio de organização temporal, a formatação da nossa capacidade de prazer segundo o ritmo do começar. O prazer básico com navegar seria o de começar, o de abrir uma página, o que precisa ser continuamente renovado pelo prazer de abrir outra porta. A onipresente oferta de "você que curtiu isso vai curtir também..." em todos os chamados sites não seria de modo algum aleatória, ela é o próprio espírito do espaço digital, o que faz com que o mais visitado lugar deste espaço seja uma ultraeficiente página de buscas, que vem a ser a empresa mais valiosa do planeta. As reflexões de um analista do mundo digital, Nicholas Carr, me influenciaram bastante neste aspecto. ${ }^{20} \mathrm{O}$ livro de Carr, muito calcado nas 
célebres reflexões de Macluhan sobre o mundo da comunicação e de Walter Ong sobre a relação entre mudanças na consciência na passagem da civilização oral para a da escrita, sustenta que nosso "cérebro", sendo a mais maleável das criações biológicas, impõe muito poucas estruturas à experiência. Ao contrário, é muito mais por ela moldado. Usar um computador, ainda mais conectado ao espaço digital como todos o são a partir de certa época, modifica o modo como percebemos, pensamos e lembramos. Uma tese basicamente afinada com as diretrizes benjaminianas de relacionar as modificações na estrutura da experiência e as técnicas dominantes. É como naquela pequena narrativa de Cortázar, na qual um sujeito descobre que ao comprar um relógio, ao assumir os hábitos que a posse do inocente objeto impõe a seu dono, ele na verdade deu a si mesmo de presente ao relógio, e não vice-versa. As séries, se as olhamos isoladamente, desconectadas dos hábitos que regem nossa percepção cotidiana, são formalmente muito semelhantes aos folhetins, e mais ainda, aos seriados de TV. Mas o hábito de assistir capítulos online em sequência de modo compulsivo, não. Existiria uma remodelagem da nossa percepção intermediando este vício.

Mas haveria algo de paradoxal nesse modo de seguir histórias dentro do espaço digital, eu sustentava: ele reforça o princípio do prazer de começar, pelo fato de que o término de um capítulo inocula o desejo de ver imediatamente o seguinte, mas mantém o espectador refém daquela mesma série. Ele representa, portanto, o paroxismo do gatilho consumista do espaço digital, mas simultaneamente o nega, pois o binge watcher permanece na trilha de uma história, nos desdobramentos de algumas personagens no tempo de uma certa ação. Diante desse paradoxo, a minha conclusão era a de que o relativo enfraquecimento da estrutura rigorosamente voltada para um fim conclusivo, que ficava bastante postergado (mas de modo algum suprimido) nas séries, estaria, no entanto, na melhor das hipóteses, criando uma espécie de apêndice no interior do espaço digital, nutrido com os mesmos materiais deste.

Mas essa conclusão não me parecia muito satisfatória. Era por demais parente do olhar apocalíptico de Carr e de Jonathan Crary ${ }^{21}$, outro autor que li na época. Fazia de um tipo de recepção a narrativas pouco mais que um mero reflexo das condições tecnológicas e sensoriais contemporâneas. Será que um hábito narrativo como esse, tão disseminado, do qual é fácil falar ridicularizando-o, é só um efeito, afinal de contas, da "infraestrutura"? Será que falar desse hábito é só uma oportunidade para engrossar o coro dos Duhamel de plantão? Notem que vituperar o presente é uma tática quase infalível de fazer alguns amigos. Mas será que um hábito estético (sim, estético, por que não?) não contém em si nenhuma virtualidade, nenhuma perspectiva que aponte para algo além dele mesmo, não para uma causa prévia, pronta e acabada, mas para um lugar de valor ainda indecidido e não apropriado por ninguém ou por nenhuma força política/econômica? Walter Benjamin e John Dewey não nos ensinam a procurar nas formas das afinidades entre uma época e uma forma artística justamente esse horizonte meio enevoado para o qual apontam e no qual ainda não chegaram e talvez nem cheguem? 
O que fortaleceu a tendência a ir em uma direção um pouco diferente da inicial, ou seja, daquela centrada na questão do enfraquecimento do enredo, fortalecimento do episódico e ligação disto com os hábitos do mundo digital, foram as minhas duas tentativas de analisar o caso do sucesso de um romance contemporâneo. ${ }^{22}$ Trata-se do quarto romance da americana Jennifer Egan, A Visit from the Goon Squad, publicado em $2010 \mathrm{e}$ traduzido no ano seguinte no Brasil como $A$ visita cruel do tempo. ${ }^{23} \mathrm{O}$ livro me caiu em mãos por acaso, um exemplar emprestado durante uma viagem, em 2014. A leitura me pegou, por vários motivos pessoais, como costuma acontecer nesses casos em que nada de exterior ou profissional nos impele a ler um livro. Sua leitura foi feita no período em que eu mais assistia a séries. Algum tempo depois, me dei conta de que a atração exercida pelo romance era parenta daquela exercida pelas séries. Nestas, o enredo oscila entre o total episódico e a subordinação a um arco de enredo não muito claro. Mesmo em uma série como Breaking Bad, cuja duração coincide completamente com o processo da descoberta, lenta e assustadora, de quem vai se tornando a personagem principal, o químico Walter White, cada temporada tem um desenvolvimento próprio, fazendo com que o tempo pareça andar em uma direção pouco definida, ao ponto de cada capítulo se constituir como uma história quase autônoma. Ao mesmo tempo, ao fim de cada capítulo algo que ficou em suspenso lança nossa expectativa para ao próximo capítulo. Mas não é para muito além do próximo capítulo que a narrativa quer atrair o nosso olhar. O romance de Egan me chamou a atenção por não propor absolutamente nenhum fim englobante, cada capítulo se sustentando por si mesmo, embora haja repetição de algumas personagens. O romance não tem direção temporal, pois os capítulos são situados aleatoriamente dentro de um certo período de algumas décadas, e duram o tempo suficiente apenas para que a situação de vida de uma personagem em uma determinada época de sua vida seja apresentada com nitidez. Mas não é uma coletânea de contos. Trata-se de uma rede de acontecimentos das vidas de um certo grupo de pessoas, que se conhecem ou estão a um conhecido em comum de distância. Nenhum desses acontecimentos é mais do que uma situação, onde acontecem algumas coisas em sequência que dizem quem é aquela pessoa, na época enfocada, o que é ser ela, naquele tempo específico. A rigor, este livro só pôde ser chamado de romance porque essa forma, desde seus primórdios, é capaz de se apropriar das mais variadas formas discursivas, como já fora notado pelos teóricos-poetas do primeiro romantismo. $\mathrm{O}$ livro de Egan faz com que o leiamos como uma espécie de romance, pois há um ar de família entre as histórias, uma recorrência de personagens, que são vistos em épocas diversas e a partir de óticas igualmente diferentes, pois cada capítulo é narrado do ponto de vista de algum deles, e este nunca ocupa o centro duas vezes. E porque, assim fazendo, põe o tempo das personagens em evidência. Descrevê-lo faz com que soe como um experimento de difícil leitura. Mas o fato é que ele funcionou comigo, ao ponto em que, como um bom folhetim, não "consegui largá-lo". Dei o livro de presente a amigos que faziam aniversário, para ter com quem conversar sobre o livro. Afinal, apesar de o livro ter feito relativo sucesso comercial, é difícil encontrar companheiros de recepção na literatura contemporânea. Mas tentei criá-los ao meu redor, a começar pelos de casa, 
inclusive a filha adolescente, e a recepção foi em geral boa.

Fiquei muito animado quando descobri diversas entrevistas da autora, que ganhou com o livro o Pulitzer e o National Critics Award, os principais prêmios literários de seu país, em 2011, o que the conferiu uma certa notoriedade midiática. Ela dizia que a série Os sopranos tinha sido influência decisiva na escrita do livro:

Durante os mesmos anos em que eu estava lendo Proust com meus amigos, assistia também a The Sopranos, que também se desdobrava numa espécie de tempo vagaroso, de certo modo em tempo real, no qual as crianças na série cresciam e todas as personagens visivelmente envelheciam. Então ali também (como em Proust) havia o sentimento da vida de alguém passando junto com o desdobramento da série. De algum modo, como eu me propus a questão de como tecnicamente realizar o que Proust fez mas de modo diferente e, mais importante, de modo mais curto, decidi que o uso de algumas das técnicas de uma série como The Sopranos poderia ser um caminho. É por aí que os dois se fundiram. Há esse enfoque lateral em The Sopranos no qual uma personagem menor subitamente se torna principal por um tempo e então sai de foco de novo, e a história englobante é às vezes quase invisível em face de subenredos e complicações que são tão envolventes que quase se esquece qual é a história, com H maiúsculo, da temporada, ou apenas se fica sabendo quando esta começa a terminar. Eu realmente gostei disso tudo, e acho que, de algum modo, quando comecei a trabalhar em A vista cruel do tempo, a ideia de misturar algumas dessas técnicas com meus objetivos conscientes de escrever um livro deve ter acontecido. ${ }^{24}$

A visita cruel do tempo mostrava era que a prosa romanesca de longa dimensão se revela, mais uma vez, como uma forma elástica o suficiente para a realização poética de virtualidades que se apresentam no mundo cotidiano. No caso, esse livro me surgiu como a realização mais plena da temporalidade que as séries prometem, mas que não cumprem integralmente. O compromisso conservador das produções das séries impede que seja abandonado esse mecanismo cultural arraigado que é a promessa de um fim, a segurança que emana da autoridade de um narrador que sabe por antecipação tudo o que vai acontecer, de um narrador que sabe quando é o fim. ${ }^{25} \mathrm{O}$ romance de Egan, mesmo com o completo abandono deste mecanismo, pois o saber de seu narrador é de outra ordem, obteve uma recepção significativa, em se tratando de uma narrativa escrita, nos dias de hoje. Digamos que ela esticou uma corda meio solta que se encontra no modo de recepção das séries, não exatamente aquela que está já muito esticada, a do vício e compulsão movidos pelos hábitos de curiosidade incitados pela internet, mas sim a da relação entre personagem e tempo. A relação entre acompanhar o desenvolvimento de uma personagem e a percepção de um modo de temporalidade na qual o receptor está implicado. 
O canal HBO, produtor de diversas séries de sucesso mundial, como a própria Os sopranos, demonstrou interesse momentâneo em adaptar o romance para o formato que o teria inspirado, mas não foi adiante no projeto, e esta desistência pode ser vista como confirmação do que acabamos de afirmar a respeito do conservadorismo da indústria de séries. Sobre este episódio do interesse do canal produtor de séries, antes da desistência, Egan especulou:

\begin{abstract}
Uma coisa interessante sobre todo esse assunto HBO é que porque isto é proposto como uma série, a ideia é que de algum modo isso vai extrapolar os limites do livro, o que por um lado é assustador, mas eu também sinto que a estrutura do livro está aberta para isso. Há inúmeros tipos de direcionamento que eu pensei em tomar e não o fiz, e eu gosto da ideia deles tomando essas direções. Eu sinto que existe uma abertura da narrativa que torna possível partir dela sem a violar. Trata-se mais do tipo de regra de investigação do que de fato ficar mexendo no que eu fiz. Eu acho. ${ }^{26}$
\end{abstract}

Aquilo a que a escritora se refere, quando fala em estrutura aberta, é exatamente o que ela diz ter trazido de uma série como Os sopranos, o desenvolvimento lateral, que reside em transformar uma personagem secundária de um capítulo em central em outra, o que ela faz em seu livro ao pular para a perspectiva desta personagem indo investigá-la em outra época, quebrando a continuidade do deslocamento temporal. Foi isso que ela conta que fez ao começar a escrever seu livro: ao terminar uma pequena história, se perguntou quem seria uma certa personagem mencionada de passagem, e passou a compor uma pequena situação em que esta então era o centro, enquanto a que ocupava o centro na primeira passava à periferia. Este era o motor da narrativa, que podia então se desdobrar infinitamente, por assim dizer, para todos os lados, e não para o fim. Reforça esta sensação lateral o fato de que a época em que se passam os capítulos não obedece a nenhuma linearidade. Mas é isso que uma série como Os sopranos não faz. O que Egan viu na série era uma virtualidade presente na forma das séries e na de sua recepção. E o que seu público leitor compreendeu, creio eu, também.

Tampouco neste caso queremos basear nosso interesse pelo romance na pressuposição de sua originalidade absoluta. Claro que seus recursos técnicos podem ser encontrados em outros romances. Mas a recepção relativamente vasta, sua vinculação histórica explicita com o universo das séries, juntamente com a percepção, dispersa pelas matérias da imprensa especializada, de que se tratava de um romance modulado pelas condições técnicas atuais, fizeram com que $A$ Visit from the Goon Squad se tornasse a sequência natural dos textos desta minha pesquisa. Para mim, isso esclarecia ainda mais que não era uma pesquisa sobre séries, mas sim sobre narrativas que, afinadas com o ambiente estético atual, tendiam a elaborar um jogo para o leitor/espectador que enfraquecia a noção de fim, ao mesmo tempo em que fortalecia a de personagem. O livro de Jennifer Egan provava que era possível uma narrativa ser lida como romance, isto é, ainda como um todo, e, ao mesmo tempo, ser centrada inteiramente nas personagens, sem qualquer arco englobante de enredo. $\mathrm{O}$ que pode, neste caso, ser aparentado ao enredo é o desenho da situação vivida pela(s) personagem(ns) no interior 
de cada capítulo. Mas esta termina no ponto em que fica claro o que é ser aquela determinada personagem, naquela época de sua vida. Um ato aparentemente importante mencionado durante o capítulo, que poderia ser o mote para seu desdobramento, é abandonado, desde que o resultado de mostrar quem é aquela personagem já tenha sido atingido. O mais frequente durante a leitura de $A$ visita cruel do tempo é que venha a primeiríssimo plano o que chamamos, em minhas tentativas de abordar o romance, de "sentimento de situação", isto é, a imersão do leitor na experiência das personagens numa dada época de suas vidas, sem a tradicional companhia da promessa de um fim já de posse de um narrador que sabe onde tudo isso vai forçosamente terminar. $\mathrm{E}$ o mais importante, para mim, não é o simples fato de que algum escritor tenha realizado este projeto, mas sim, muito mais, que este tenha sido recebido de forma significativa, e compreendido. Por significativa, aqui, entendo uma recepção não só relativamente ampla, mas uma identificação, em artigos e resenhas, que apontasse para o caráter histórico da obra, sua conexão com as condições da experiência atual, e o livro de Egan atende às duas exigências. ${ }^{27}$

Dentro da busca paralela por autores que teorizassem de modo explícito sobre o tema da experiência relacionado ao da narrativa ou à arte em geral, encontrei não apenas o referido John Dewey, mas também o trabalho de Monika Fludernik, uma teórica alemã importante dentro do campo científico da narratologia. Digo científico porque a autora procura estabelecer um modelo teórico definitório para abarcar de modo o mais abrangente e coerente o possível toda e qualquer narrativa. Mas essa autora me chamou a atenção porque foi a primeira vez que vi alguém tentar definir narrativa abdicando de qualquer centralidade para a noção de enredo. Mais do que enredo, "experiencialidade" seria o ponto central deste modelo definitório. Experiencialidade, em um texto, em um poema ou em uma narrativa audiovisual, seria o convite a se colocar no jogo de repetir a experiência de alguém. Trata-se de um jogo em que se é convidado a participar de um ser-em-uma-situação (na falta de termo ideal para traduzir a palavra predileta da autora, embodiment: ser encarnado, o ter um corpo como sinônimo de existência concreta, espaço temporal). Em termos de vocabulário heideggeriano, diria "ser-no-mundo", estar lançado em uma disposição e compreensão junto às coisas deste mundo e dos outros. Ricoeur lança mão desta expressão quando fala que seguir uma narrativa é fazer a fusão entre o "mundo do leitor" e o "mundo do texto". ${ }^{28}$ Nos termos da narratologista Monika Fludernik, pode haver narrativa sem enredo, não pode é não haver personagem, numa certa inversão da sentença aristotélica. ${ }^{29} \mathrm{O}$ participar do mundo do texto significa a evocação da presença de um "experienciador humano". Ora, é de identificação com personagens que Fludernik está falando. Há que haver personagem, mas não é necessário prometer um enredo claro, um design costurando todos os momentos. Em outros termos, o episódico pode sutilmente prevalecer, desde que um personagem ou alguns personagens se façam presentificar de alguma forma consistente, mesmo que fragmentária e sem continuidade causal entre suas aparições, como o faz Egan em seu livro. Anatol Rosenfeld, no ensaio "Literatura e personagem", faz também uma vinculação preferencial entre narrativa ficcional e presença de personagem, de um "experienciador": 
"Em todas as artes literárias e nas que exprimem, narram ou representam um estado ou estória, a personagem realmente 'constitui' a ficção". ${ }^{30} \mathrm{E}$, como para Fludernik, a distância da narrativa de ficção para com a historiografia é um ponto de honra para Rosenfeld, ao contrário do que é defendido por Ricoeur: "Numa obra histórica pode constar que Napoleão acreditava poder conquistar a Rússia; mas não que naquele momento, cogitava essa possibilidade". ${ }^{31}$; "As pessoas (históricas), ao se tornarem ponto zero de orientação, ou ao serem focalizadas pelo narrador onisciente, passam a ser personagens; deixam de ser objetos e transformam-se em sujeitos, seres que sabem dizer 'eu'." 32

Acredito poder afirmar que ambos os aspectos que contrapomos aqui, ou seja, a linha invisível do enredo e a presença quase palpável da personagem, convivem em todas as narrativas. Não há personagem sem um mínimo de articulação entre as ações narradas que dizem respeito a ele. Mas a predominância ou a preferência por um ou outro aspecto por parte do que chamamos hoje de público, ou seja, por parte daqueles que em uma determinada época demonstram mais afinidade e facilidade em seguir este ou aquele tipo de história, é indiciador de diferenças na estrutura da experiência. Narrativas onde o episódico é mais visível do que a unidade de enredo me parecem ser uma tônica do nosso tempo, muito embora essa tendência já estivesse sendo desenhada, como o defende Forster, pela arte do romance. O que passei a perceber, especialmente após os trabalhos sobre o romance de Jennifer Egan, é que essas narrativas não são apenas fracas de enredo, mas são fortes em personagens. Necessidade de personagens de forte presença, portanto, é uma marca de nossa época. Isto é um dado que me parece importante, desde que consideremos importante tentar identificar os traços gerais da época em que estamos. Podemos especular, pegando carona em Hans Gumbrecht (que não trata especificamente deste nosso tema, a personagem), que este foco em "experienciadores", em detrimento da atenção à linha condutora do enredo, é talvez sintoma de uma certa carência moderna do que ele chama de "presença". O autor tenta, por um lado, retraçar um projeto em curso na cultura e na filosofia desde, por exemplo, Descartes, até os dias de hoje, de esvaziamento do valor da presença, de modo a mostrar que o sonho da ubiquidade e da disponibilidade total, oferecido (e aceito por todos) hoje pela tecnologia da comunicação, é um desdobramento totalmente consequente. Estar em todos os lugares, através de dispositivos cada vez mais onipresentes, seria não estar especificamente em lugar algum. O mesmo se refere ao tempo. Por outro lado, ele chama de "redenção" os movimentos que buscam, em meio a esta destruição da presença, justamente o seu oposto, ou seja, a reinvenção da presença, do aqui-e-agora. ${ }^{33}$

Poderíamos colocar o fenômeno de adicção em séries do tipo de Breaking Bad, ou seja, aquelas com nítida continuidade de personagens muito bem delimitadas, no rol de tentativas de burlar a despresencialização predominante em nosso atual meio tecnológico? Talvez, muito embora o aspecto da adicção possa significar também uma incapacidade de tomar qualquer distância crítica do que está presente. A busca por 
presença através de personagens pode ser vista como escapatória à transferência do espaço vital para a era da ubiquidade, a nossa época da abdicação da presença no aqui e agora em prol da disponibilidade absoluta para as redes de comunicação social? Ao visitar museus em qualquer lugar do mundo, por exemplo, chama a atenção o gesto corriqueiro dos visitantes de fotografar os quadros com o celular sem sequer parar para olhá-los, postergando para um remoto depois (e transferindo para um vago e indefinido quem) a experiência efetiva de vê-los uma vez que seja. Contra esse impulso, que está mais presente em nossa vida cotidiana do que gostaríamos de admitir, pode ser que o gosto por acompanhar personagens represente um inconsciente foco de resistência. Não que deste hábito nos pareça que vá surgir algum impulso revolucionário, mas ele sintomatiza uma carência por clareza e nitidez da imagem do outro e de nós mesmos como um outro, sem a fragmentação do mundo informativo, sem a dispersão extrema da atenção, ou seja, a personagem nos oferece algo que a consciência que podemos ter de nós mesmos e dos outros se mostra cada vez menos apta a realizar, nas atuais condições. Um romance como o de Jennifer Egan, portanto, me surgiu, neste percurso, como um feliz exemplo de uma obra que realmente procura ir ao encontro das condições da experiência contemporânea, mas no sentido de realmente propor uma experiência estética desta, na qual realmente se pode aprender um novo modo de habitar o tempo, o que não pode advir nem do pânico diante das mudanças nem da adesão cega. Nossa pesquisa, portanto, precisa agora reforçar os passos já percorridos e encontrar novos exemplos de modulações estéticas para esta questão, seguindo a via do "método" a que aludimos no início deste texto. Qualquer sugestão é muito bem vinda.

\section{* Bernardo Barros Oliveira é professor associado do Departamento de Filosofia da UFF.}

${ }^{1}$ Cf. BENJAMIN, W. "O narrador. Considerações sobre a obra de Nikolai Leskov". In: Sobre arte técnica, linguagem e política. Tradução de Maria Amélia Cruz. Lisboa: Relógio D’Água, 1992.

2 "É cada vez mais raro encontrar pessoas que saibam narrar qualquer coisa com correção. Quando alguém manifesta o desejo de ouvir uma história, é cada vez mais frequente surgir o embaraço entre as pessoas que o rodeiam". Ibidem, p. 28.

${ }^{3}$ Cf. BENJAMIN, W. "A obra de arte na época de sua reprodutibilidade técnica". In: Benjamin e a obra de arte. Técnica, imagem, percepção. Tradução de Marijane Lisboa. Rio de Janeiro: Contraponto, 2012.

${ }^{4}$ Por exemplo: "O cinema é a forma de arte que corresponde aos grandes perigos existenciais com que se defrontam os homens contemporâneos. A necessidade de se submeter a efeitos de choque é uma adaptação dos indivíduos aos perigos crescentes. O filme corresponde a mudanças profundas no aparato receptivo, como as mudanças vivenciadas no plano privado por todo pedestre no meio do tráfego de uma grande cidade ou, na dimensão histórica, por todos os cidadãos contemporâneos". Ibidem, nota n. 29, p. 39.

5 O Globo, 13/04/2014. Disponível em <http://oglobo.globo.com/cultura/ricardo-piglia-revela-silenciosocotidiano-da-violencia-12180448>. Acesso em 14.02.2016.

6 "Decidí tomarme las escenas de Mad Men como lecciones para reconciliarme con el encanto de dedicarse a las formas breves, de escribir cuentos, en suma. Me reconcilié con el arte de contar 
por el placer mismo de contar: una actividad de la que, sin desearlo del todo, me había ido apartando en los últimos tiempos, quizá por dedicarle cada día más atención a lo ensayístico". VILLA-MATAS, H. "Peggy no se casó". El País, 27/03/2015, Disponível em: http://cultura.elpais.com/cultura/2015/03/27/television/1427473481_503083.html. Acesso em 14.02.2016.

${ }^{7}$ Cf. O Globo, 30/09/2013. Disponível em <http://oglobo.globo.com/cultura/revista-da-tv/audiencia-do-ultimoepisodio-de-breaking-bad-cresceu-442-10203421>. Acesso em 14.01.2015.

${ }^{8} \mathrm{O}$ termo binge watching foi detectado pelo dicionário Oxford como a terceira mais importante entre as novas palavras ou expressões na língua inglesa, no ano de 2013. Cf. $<$ http://blog.oxforddictionaries.com/press-releases/oxford-dictionaries-word-of-the-year-2013/>. Acesso em 14.01.2015. Cf. tb. o verbete na Wikipedia, disponível em <http://en.wikipedia.org/wiki/Binge-watching>. Acesso em 14.01.2015. Já o dicionário Collins a elegeu como a "palavra do ano" de 2015. Cf. <http://www.theguardian.com/books/2015/nov/05/binge-watch-2015-word-of-the-year-collins>. Acesso em 14.01.2015.

${ }^{9}$ Peço licença então para me citar. Proferi a comunicação "Experience and narrative in the digital era: the binge-viewing case" no Encontro de 2015 da International Society for Information Studies, em Viena. Uma nova versão deste trabalho, intitulada "As narrativas seriadas e a experiência contemporânea", foi publicada no n. 36 da revista O que nos faz pensar, da Puc-Rio. Estes dois trabalhos foram precedidos por um ainda inédito, intitulado "Experiência e narrativa na era digital". Neste último, assim como no já publicado, são citados alguns dos inúmeros artigos que encontrei na imprensa, especialmente americana, mas também na brasileira, sobre o fenômeno. Um dos mais interessantes, por abordar o aspecto econômico, comportamental e até psiquiátrico do novo hábito é o de John Jungersen, "Binge Viewing: Tv's lost weekends", no Wall Street Journal de 13 de julho de 2012. Disponível em <http://www.wsj.com/articles/>. Acesso em 14.01.2015.

${ }^{10}$ DEWEY, J. Arte como experiência. Tradução de Vera Ribeiro. São Paulo: Martins Fontes, 2010, p. 63.

${ }^{11}$ Referindo-se à acusação de Duhamel de que o cinema é "um passatempo para hilotas, uma diversão para criaturas sem instrução...", Benjamin diz: "Encontramos aqui a velha acusação de que as massas buscam distração, enquanto a arte exige recolhimento por parte do espectador. É um lugar comum. Vale perguntar se ele oferece uma boa perspectiva a partir da qual possamos entender o cinema". BENJAMIN, W. "A obra de arte na época de sua reprodutibilidade técnica". Op. cit., p. 30.

${ }^{12}$ FLUDERNIK, M. Towards a Natural Narratology. London: Routledge, 1996; FORSTER, E. M. Aspectos do romance. Tradução de Maria Helena Martins. São Paulo: Globo, 1998; WATT, I. A ascensão do romance. Tradução de Hildegard Feist. São Paulo: Companhia das Letras, 2010.

${ }^{13}$ Falando de Thomas Hardy, Foster diz: "[...] Hardy dispõe os acontecimentos enfatizando a causalidade, o fundamento é um enredo, e as personagens têm a ordem de se submeter às exigências deste. Com exceção de Tess (que dá a sensação de ser maior que seu destino), este aspecto de sua obra é insatisfatório. [...] A fatalidade acima de nós, não a fatalidade agindo através de nós [...] Em outras palavras, exigiu-se das personagens uma contribuição demasiada ao enredo [.... Tanto quanto posso deduzir, essa é a falha que se estende por todos os romances de Hardy: enfatiza a causalidade com mais força do que seu gênero literário permite". FORSTER, E. M. Op. cit, pp. 89-90.

14 "[...] o elemento mais importante é a trama dos fatos [pragmáton systasis], pois a Tragédia não é imitação de homens, mas de ações e de vida [...] Daqui se segue que, na tragédia, não agem as personagens para imitar caracteres, mas assumem caracteres para efetuar certas ações [...] Sem a ação não poderia haver Tragédia, mas poderia havê-la sem caracteres". ARISTÓTELES. Poética. Tradução de Eudoro de Souza. São Paulo: Ars Poética, 1993, p. 41 (1450a 17-25).

${ }^{15}$ Referindo-se a uma obra de outro romancista excessivamente preocupado em enquadrar as personagens nas exigências de um enredo que não brota delas mesmas e de suas necessidades, 
Forster diz: "Aproximando-se do final [...] há uma tentativa para elevar o enredo a uma simetria aristotélica, a transformar o romance num templo onde mora a intepretação e a paz". FORSTER, E. M. Op. cit., p. 88.

${ }^{16}$ Cf. RICOEUR, P. Temps et récit 1. L'intrigue et le récit historique. Paris: Éditions du Séuil, 1983, pp. 68-79.

${ }^{17}$ Cf. RICOEUR, P. Temps et récit 2. La configuration dans le récit de fiction. Paris: Éditions du Séuil, 1984, pp. 17-58.

${ }^{18} \mathrm{O}$ livro de Frank Kermode, The Sense of an Ending. Studies in the Theory of Fiction. (Oxford: Oxford University Press, 2000) exerceu um grande fascínio sobre mim, muito antes de esta pesquisa ter tomado forma. A sua tese mais importante é a de que a noção de fim é o ponto capital quanto à forma como cada época compreende o tempo. $O$ tema tem para ele uma abrangência que vai muito além do literário. Os esquemas de começo, meio e fim predominantes nas formas de narrativas mais praticadas em uma época são derivações de modelos de História, com $\mathrm{H}$ o mais maiúsculo o possível. Kermode, de modo semelhante a Ricoeur, que tem nesse livro uma das bases mais influentes para seu Tempo e narrativa, defende a noção de fim como um elemento inalienável da narratividade.

${ }^{19}$ Ricoeur, em Soi-même comme un autre, no capítulo 6, especialmente nas páginas 167 a 180 , retoma o tema da personagem, e aborda a intimidade entre personagem e enredo mais do que 0 faz, talvez, em Temps et récit: "La personnage, comprise comme personnage de récit, n'est pas une entité distincte de ses 'experiences'". RICOEUR, P. Soi-même comme un autre. Paris: Éditions du Seuil, 1990, p. 175.

${ }^{20}$ CARR, N. The Shalow. What the Internet is Doing to Our Brains. New York: W. W. Nortn \& Company, 2010.

${ }^{21}$ Como mostra Jonathan Crary, estudioso da historicidade da percepção, o mundo atual é o da constante substituição dos artefatos que regem nosso dia a dia, de modo a que nunca nos vejamos em uma situação de relativa estabilidade (cf. 24 / 7: Capitalismo tardio e os fins do sono. Tradução de Joaquim Toledo Jr. São Paulo: Cossac Naif, 2014.) Mal se tem tempo de assimilar uma nova tecnologia, já temos de correr para nos adaptar a outra, sob o risco de nos tornarmos cronicamente obsoletos. Os dispositivos não são usados por tempo o suficiente para passarem para um segundo plano, mas permanecem na frente da cena. O medo da obsolescência, como nota Jennifer Egan em entrevista, acomete até os mais jovens dos jovens, o que teria feito, segundo ela, que o seu $A$ visita cruel do tempo fosse bem aceito por este público, para quem um romance sobre o tempo faz surpreendente sentido.

${ }^{22}$ Produzimos dois ensaios sobre o romance de Jennifer Egan, ambos em vias de publicação como capítulos de livro: "Um romance sobre o tempo na época das séries" (CHARBEL, Felipe; GUSMÃO, Henrique Buarque de; MELLO, Luiza Larangeira da Silva (orgs.). As formas do romance: estudos sobre a historicidade da literatura. Rio de Janeiro: Ponteio, 2016.) e "O fim do fim: um romance contemporâneo dialoga com o tempo seriado", no livro do evento O trágico, o sublime e a melancolia, realizado na UFMG em 2015.

${ }^{23}$ EGAN, J. A Visit from the Goon Squad.New York: Alfred A. Knopf, 2010. Edição Kindle. A Visita cruel do tempo. Tradução de Fernanda Abreu. Rio de Janeiro: Intrínseca, 2011.

24 "During the same years that I was reading Proust with my friends, I was also watching The Sopranos, which also unfolded at a leisurely, kind of real time pace, through which the children in the series grew up, and all of the characters visibly aged. So again there was a sense of one's own life passing in tandem with the unfolding of the series. Somehow, as I asked myself the question of how to technically accomplish what Proust accomplishes but in a different and, most importantly, compressed way, I decided that using some of the techniques of a series like The Sopranos might be one way to try to do that. That's the way in which they fused. There's this lateral approach in The Sopranos in which a minor character suddenly becomes a major character for a while and then 
goes out of focus again, and the overarching story is almost invisible at times in the face of subplots and complications that are so engrossing that one almost would forget what the story, capital S, of the season was, or not even know it until the season began to conclude. I really liked all of that, and I think in some way, when I sat down to work on A visit from the Goon Squad, the idea of merging some of those techniques with my conscious goal of writing a book about time must have happened". Tradução nossa. Disponível em: <http://www.popmatters.com/column/154523-celebrating-thepossibilities-of-fiction-a-conversation-with-jennife/>. 2012. Acesso em 11/06/2015.

${ }^{25}$ Claro que existem séries que duram décadas, em diversas partes do mundo, seja no rádio ou na TV, e em que nenhum aceno de fim se faz necessário. Mas estas são acompanhadas dentro de um outro modelo de recepção, que é a da exibição em horário fixo. No caso das séries na internet, o modelo de narrativas estritamente episódicas, como Dr. House ou Friends, mais presentes na fase de exibição em canais de TV, foi preterido em termos de séries com promessa de fim, como o atesta uma rápida olhada nos títulos de maior sucesso nesta fase.

26 "One thing that's interesting about this whole HBO thing is that because it's proposed as a series, the idea is that in some sense it will ultimately move outside the bounds of the book altogether, which is scary in one way, but I also feel like the structure of the book is open to that. There are all kinds of directions I thought of going in and I didn't, and I like the idea of them going in those directions. I feel like there's an openness to the narrative that makes it possible to part from it without violating it. It's more about some kind of rules of inquiry than actually sticking to what I've done. I think." FEELDMAR, J. "Talking with Jennifer Egan". Disponível em: http://gothamist.com/2011/07/08/jennifer_egan.php. Gothamist, 2011. Acesso em 14/10/2015.

${ }^{27}$ Um dos artigos que fazem de modo mais consistente esta relação entre a obra de Egan, incluindo seus três romances publicados antes de $A$ visita cruel do tempo, e as condições da vida no mundo tecnológico atual é o de MISHRA, P. " Modernity's Undoing”. Londo Review of Books, 2011. Disponível em: <http://www.lrb.co.uk/v33/n07/pankaj-mishra/modernitys-undoing>. Acesso em 14.01.2015.

${ }^{28}$ RICOEUR, P. "La fonction herméneutique de la distanciation". In: Du texte à l'action. Paris: Éditions du Seuil, 1986, pp. 125-129.

29 "In my model there can therefore be narratives without plot, but there cannot be any narratives without a human (anthropomorphic experience of some sort at some narrative level)". FLUDERNIK, M. Op. cit., p. 9.

${ }^{30}$ ROSENFELD, A. "Literatura e personagem". In: CANDIDO, A.(org.) A personagem de ficção. São Paulo: Perspectiva, 1981, p. 31.

${ }^{31}$ Ibidem, p. 24.

32 Ibidem, p. 26.

${ }^{33}$ Cf. GUMBRECHT, H. U. Production of Presence. What Meaning Cannot convey. Stanford: Stanford University Press, 2007, especialmente pp. 138-139. Poderíamos até arriscar afirmar que Gumbrecht recai na alternativa de contrabalançar o caráter decadente e impotente da experiência com alguma modalidade de intensidade vivencial, nisto seguindo a gangorra de valores atribuídos ao par Erfahrung/Erlebnis, em especial no fim do séc. XIX e início do XX. Cf. JAY, M. The Songs of Experience. Modern American and European Variations on an Universal Theme. Berkeley: University of California, 2005. Segundo Jay, ora se confere valor ao caráter durativo e transmissível da experiência, Erfahrung, em detrimento do caráter fugaz e solipsista da experiência vivida, Erlebnis. Ora se dá justo o contrário, e é talvez o que pode ter acontecido com Gumbrecht e seu elogio à força vivencial de presença. No entanto, suas análises da cultura contemporânea possuem o grande mérito de não se fecharem em um pessimismo apocalíptico como o faz, por exemplo, o acima citado Jonathan Crary. 